\title{
ADVANCED METHODS OF CORROSION MONITORING- A REVIEW
}

\author{
Nikesh Ganesh Rathod S.M. ASCE ${ }^{1}$, Narayan Chandra Moharana ${ }^{2}$ \\ ${ }^{l}$ M.Tech Student, School of Civil Engineering, KIIT University, Bhubaneswar, Odisha, India \\ ${ }^{2}$ Assistant Professor, School of Civil Engineering, KIIT University, Bhubaneswar, Odisha, India
}

\begin{abstract}
Presently it is found that RC structures decays with respect to time before its design life period is achieved. Many researchers found the principle cause of degradation is corrosion of steel reinforcement. Surrounding environment and some physical properties are responsible for corrosion of steel in concrete. Formation of cracks due to corrosion is the key indicator end of the service life. Corrosion of steel reinforcement starts well before the formation of the cracks and cannot be detected by visual means and can be determined by some non-destructive means. Therefore, the assessment of residual capacity, conservation and arrangement for renovation of those structures needs Non-Destructive inspection and monitoring methods that detect the corrosion at early stage. Suitably monitoring the structures for corrosion problem and taking appropriate measurements at right time could affect huge savings. With the help of corrosion monitoring we can get wide-ranging info about fluctuating conditions of structure in time. The methods used for the assessment of corrosion are Open Circuit Potential (OCP) method, Surface Potential method, Linear Polarization Resistivity (LPR) measurement and many more but didn't give current corrosion stage in $R C$ structures. Present study include the review of some modern methods like Acoustic Emission, Galvanic Monitoring Probe, Potentio-Dynamic, High Frequency UV and Fibre Optics method summarising their merits, demerits and suitability in field use. This will be helpful for other researchers gaining fundamentals of corrosion monitoring, different methods and equipment. Also will be use full to continue further research and development of commercial instruments for precise determination of corrosion status in existing structures.
\end{abstract}

Keywords: Electrochemical, Corrosion, Monitoring, Restoration, Polarization, Emission. $* * *$

\section{INTRODUCTION}

The most widely produced and consumed material in construction industry is Reinforced Cement Concrete (RCC). From the beginning RCC is assumed to be a durable material but this misconception came to an end when it was found that the most important and predominant factor causing premature deterioration of RCC is Corrosion of Steel Reinforcement. The problem has now reached worrying extents. The foremost causes of corrosion are (i) local depassivation and (ii) comprehensive depassivation of concrete around the reinforcing steel. The reason for depassivation of concrete is the result of ingress of chloride ion in chloride laden environment and also because of acidification of interstitial pore solution by ingress of $\mathrm{CO} 2$ from atmosphere ${ }^{1-2}$. The presence of harmful chloride ions in concrete is an outcome of external impurity prior to construction or polluted ingredients on manufacture of mix.

After the initiation of corrosion, rise of corrosion products (iron oxides and hydroxides) in a limited space around steel in concrete increases volume by 1.7 to 6 times than original steel volume involved in corrosion ${ }^{3}$ setting up expansive stresses causing spalling and cracking of concrete cover. Invasion of $\mathrm{O} 2$ and water facilitates and accelerates rapid corrosion losing structural integrity at this stage. Corrosion is initiated sufficiently before the cover cracking which is key indicator of end of service life. To recover the structural integrity, it requires repair operations which are quite complex and life expectancy of repair is also limited involving a high repair and maintenance cost. Corrosion cannot be detected by visual inspection and but an enormous savings can be made if at an early stage Non-Destructive inspection and monitoring technique for quality control, preservation and forecasting for rebuilding of these structures are done.

The methods used for the assessment of corrosion are Open Circuit Potential (OCP) method, Surface Potential method (SP), Linear Polarization Resistivity (LPR) measurement and many more but didn't give current corrosion stage in RC structures. Present study include the review of some modern methods like Acoustic Emission, Galvanic Monitoring Probe, Potentio-Dynamic, High Frequency UV and Fibre Optics method summarising their merits, demerits and suitability in field use. This will be helpful for other researchers gaining fundamentals of corrosion monitoring, different methods and equipment. Also will be useful to continue further research and development of commercial instruments for precise determination of corrosion status in existing structures.

\section{PHENOMENON OF CORROSION}

Various chemical reactions and electrical current are involved in corrosion. Corrosion in reinforcing steel starts after the depassivation of coating on steel because of carbonation or in company of chloride ions. Heterogeneities in exterior of the steel and the heterogeneous environment of concrete cause local differences in the electrolyte producing a region to act as an anode and another region to act as a cathode of steel reinforcement. Because of this, 
there is an electrical connection between the two and the pore water in concrete acts as electrolyte setting up the electrochemical process in concrete.

The $\mathrm{pH}$ of concrete, in the lack of chlorides and in noble quality concrete is usually in the range of $11.5-13.5^{1}$. This $\mathrm{pH}$ reduces and loss of passivation layer takes place when carbon/sulphur dioxide from atmosphere dissolves in water to form weak carbonic/sulphuric acid which enters in concrete through pores. Chlorides first attack passivating ferrous oxide (Fe2O3) layer on steel reinforcement. After the loss of passivation layer, concrete becomes highly susceptible to electro-chemical corrosion. The diluted chloride ions establishes anodic and cathodic sites on rebars forming electro-chemical corrosion cell. The reduction in cross section of rebar at specific sites is a result of pitting corrosion which leads to sudden failure of structural member. The chemical reactions involved in this process are shown in Figure 1.

The conditions responsible for corrosion are damage of passivation, occurrence of dampness and occurrence of oxygen. If any one of these is absent, there will be no corrosion. Or else, rate of corrosion can be slow down by limited amount of dampness and oxygen. During the corrosion process, there is no "net use" of chloride ion ${ }^{5}$. In order to maintain the corrosion reaction, only water, oxygen and conductive medium is needed once enough chloride ions reach to break the passivation layer around steel. Temperature plays an important role in corrosion (as it is a chemical process) ${ }^{5}$. According to general rule for the rate of chemical reaction, for every $25^{\circ} \mathrm{F}$ increase, the reaction rate doubles. Therefore, higher the temperature the faster the corrosion reaction occurs.

\section{CORROSION MONITORING TECHNIQUES}

Corrosion is the most dangerous phenomenon occurring in RC structures. It can be observed only after formation of cracks on the surface of concrete cover which indicate end of service life. After carbonation and chloride attack, the steel reinforcement is subjected to expansive stress resulting in cracks. Hence, in order to safeguard RC structure from corrosion various monitoring techniques are developed with an intent to measure the rate of corrosion. This review paper presents some of the developed corrosion monitoring techniques with their advantages, disadvantages and suitability of application.

\subsection{Open Circuit Potential (OCP) Technique}

Metals have a tendency to react with environment to develop potential. In RC structures, concrete acts as an electrolyte which develops potential in steel reinforcement. The working principle of OCP technique is to measure corrosion potential of rebar in comparison with standard reference electrode as shown in Figure 2. The most regularly standard reference electrode used are saturated calomel electrode (SCE), copper/copper sulphate electrode (CSE), silver/ silver chloride electrode.
Various techniques are developed providing the cause, detection and rate of corrosion ${ }^{6}$. The Half Cell Potential (HCP) measurement is main method for detecting corrosion. The use and interpretation of OCP for routine inspection of RC structures is defined in the ASTM C876 Standard Test Method for Half-Cell Potential (HCP) of Reinforcing Steel in Concrete ${ }^{2,7}$. Potential readings obtained from HCP are not satisfactory therefore, complimented by other methods because of wide variation in corrosion rate in narrow range of potential ${ }^{8}$. A commonly applied electrochemical technique is used to diagnose huge quantity of data collected from a large structures for corrosion risk by plotting a potential map as per ASTM C876-91 ${ }^{9}$.

OCP method is a useful Non Destructive Technique (NDT) for finding out anodic and cathodic sites delivering information for corrosion probability. The method is not popularly used because it fails to indicate the rate of corrosion in RC structure ${ }^{10}$.

\subsection{Surface Potential (SP) Technique}

An electric current flow takes place between anodic and cathodic sites through the concrete during corrosion process which can be sensed by measuring potential drop in concrete. Detection of probability of corrosion and identification of anodic and cathodic regions can be done without any electrical connection to rebar using Surface Potential (SP) measurement technique. This is a NonDestructive Technique (NDT) used to measure surface potential using two reference electrode. One electrode of which is kept fixed on symmetric point while other is moved alongside the structure on the nodal points. The potential of mobile electrode against static is measured using high impedance voltmeter when placed at nodal point. The probability of corrosion is more when potential variance between anodic and cathodic regions is more ${ }^{11}$. Figure 3 shows schematic representation of SP method.

The form of steel rebar embedded inside the concrete can be known with this technique but it is not feasible to use because it can only be used in laboratory and do not give real time corrosion monitoring of $\mathrm{RC}$ structure at site.

\subsection{Linear Polarisation Resistance (LPR)}

\section{Measurement}

LPR monitoring is a quick and non-intrusive technique demanding only a connection to the steel reinforcement to assess prevalent corrosion of reinforced steel in RC structures. The LPR data obtained gives more thorough info than a simple potential study providing prompt corrosion degree of the steel reinforcement which is useful in determining the optimum remedial strategy ${ }^{2}$.

LPR measurements are obtained by disturbing the equilibrium potential of the reinforcing steel. It can be done either potentio-statically i.e. by altering the potential of the steel reinforcement by a static amount, $\Delta \mathrm{E}$ and monitoring the current decay, $\Delta \mathrm{I}$ after a fixed time or by galvano- 
statically i.e. by applying a small fixed current, $\Delta \mathrm{I}$ to the reinforcing steel and observing the potential change, $\Delta \mathrm{E}$ after a fixed time period. The conditions in both cases are so selected that variation in potential, $\Delta \mathrm{E}$ falls in the linear Stern-Geary range of $10-30 \mathrm{mV}^{11}$. The calculation of polarization resistance, $\mathrm{Rp}$ of the steel is done by,

$$
R_{p}=\Delta E / \Delta I
$$

From the above equation,can be obtained by

$$
I_{\text {corr }}=B / R_{p}
$$

Where B is Stern-Geary constant. The value for active steel is $25 \mathrm{mV}$ and for passive steel $50 \mathrm{mV}$ is adopted ${ }^{11}$. Corrosion current density, icorr, can be determined if surface area of steel, A which is polarised is known:

$$
i_{\text {corr }}=I_{\text {corr }} / A
$$

The remaining service life can be obtained by extrapolating the present residual strength of the structure. The method is not used because it requires mathematical calculation for calculating corrosion rate.

\subsection{Acoustic Emission (AE) Technique}

Acoustic Emission (AE) commonly describes a technique as well as physical phenomenon. It is well-defined as a natural phenomenon of momentary elastic wave produced by quick discharge of energy from localised source inside the material when subjected to stress ${ }^{13-14}$. It is a non-intrusive method which can be used for global and local damage and can also be easily deployed. The plastic distortion and crack progress are the primary sources of AE. The method is useful for detecting real time corrosion and is highly sensitive to mechanical, physical or chemical damage as a source of energy. In order to capture the events taking place in a bulk material one or more $\mathrm{AE}$ sensors are used. Piezoelectric transducer, a device which converts mechanical energy into electrical signal is used as $\mathrm{AE}$ sensor ${ }^{13}$.

To obtain AE signals two unlike approaches are used HDD and $\mathrm{TDD}^{15}$. Hit Driven Data (HDD) is a edge measured approach. In this, when AE signal voltage exceeds a predefined edge AE wave data is acquired. The parameters which are used include Amplitude, Duration and Signal Strength. On the other hand, Time-Driven Data (TDD) is free of edge setting. AE wave is recorded at a constant rate, every $5 \mathrm{sec}$. for an interval of pre-set length, each wave of 5 sec. when continuous AE phenomenon occurs TDD becomes the best option because of fixed rate acquisition. The parameters which are used include Average Signal Level (ASL) and Absolute Energy (AbE). M. Di Benedetti et al. ${ }^{15}$ discussed the commonly used parameters in detailed and presented an fast-tracked corrosion and nonstop AE monitoring test arrangement providing significant info on the features of the corrosion circuit, continuous measurement procedure, selection of $\mathrm{AE}$ sensors, and $\mathrm{AE}$ parameter setting for data acquisition. The conclusion made are: (i) to low power conditions the best suited approach is found to be TDD than HDD (ii) due to burst nature of phenomenon TDD cannot be used to recognise the nucleation of cracking (iii) corrosion may be studied as a non-stop occurrence by increased duration of AE signals.

Tonphong Kaewkongk et al. ${ }^{13}$ studied the AE technique by focussing on initiation and propagation of corrosion. They used Potentiodynamic method in 3 electrochemical cell and also Tafel plot to calculate current (icorr) which was then used for determining corrosion rate (in milli-inches/year) ${ }^{13}$, 16 from,

$$
\text { Corrosion Rate }(M P Y)=\frac{0.13 i_{\text {corr }(E . W .)}}{d . A}
$$

Where,

E.W. = equivalent weight (in g/eq.)

$\mathrm{A}=$ Surface Area of Steel (in $\mathrm{cm}^{2}$ )

$\mathrm{d}=$ Density (in $\mathrm{g} / \mathrm{cm}^{2}$ )

$0.13=$ metric and time conversion factor

The icorr is found to be 0.813 mmpy (millimetre per year). They concluded that $\mathrm{AE}$ provides timely detection of the corrosion presence, effective to implement and can be approved to envisage correctly from AE characteristics and their behaviour of the corrosion rate in industry. Jesé Mangual et al. ${ }^{14}$ investigated AE as a resource to identify, illustrate, and trace chloride-induced corrosion in its initial phases, with depassivation of pre-stressing elements and the build-up of corrosion by products. Based on their experimental study, they made the following conclusions: (i) comparing the outcomes obtained electrochemically or through visual inspection between early stages of corrosion, intensity analysis was able to differentiate (ii) as a result of passivity collapse along reinforcement AE data facilitated the accurate detection of source location (iii) the amount of slope in increasing signal strength versus time curve shows that $\mathrm{AE}$ is proficient of identifying discriminating between initial corrosion phases.

AE technique has applications in chemical and petrochemical industry to sense stress corrosion cracking, pitting, and crevice corrosion in stainless steel. Efforts are made in detecting and localising of the commencement and development of cracks initiating from the corrosion of steel reinforcement in concrete and good results are have been achieved. Ohtsu and Tomoda ${ }^{17}$ found that AE can also provide cautions of initial phase of corrosion therefore can be linked with the severity of corrosion. 


\subsection{Galvanic Monitoring Probe}

Half Cell Potential (HCP) is a widely used method to determine behaviour of steel reinforcement to corrosion but fails in providing the quantitative information on rate of corrosion. Based on electrochemical theory, a Galvanic Polarisation Probe method was used in RC structures in 1920 for the first time yielding the results similar to current and potential ${ }^{18}$. This technique uses the actively corroding steel as anode and passivized steel as cathode making it as galvanic cell and open circuit potential difference measured was several hundred millivolts before galvanic coupling.

Joost Gulikers ${ }^{18}$ designed a probe in order to monitor the rate of corrosion in reinforcing steel which can be used in the range of aggressive chloride content concrete environment. The probe measures the difference with stretch of polarising galvanic current, corrosion potential, concrete resistance and temperature. He concluded that, this method can be used as Non-Destructive technique to determine the actual rate of corrosion be confirming in laboratory using galvanic experiment. The areas requiring research include reliable electrodes and contacts, electromagnetic interference and stray current along with short and long time environment condition for choosing measurement schedule.

Advances in Galvanic Anodes led to significant increase in the use for protecting steel reinforcement in RC structures. Sacrificial passive protection systems, Impressed current cathodic protection, Sacrificial zinc anodes, etc. ${ }^{5}$ are some developed methods. Sacrificial anodes using Aluminium (Al), Magnesium $(\mathrm{Mg})$ or Zinc ( $\mathrm{Zn})$ are mostly used for galvanic protection. Zinc is most popularly used because of its high corrosion efficiency, rate of expansion is relatively low than other metals (like $\mathrm{Al}, \mathrm{Mg}$ and Steel), increases $\mathrm{pH}$ in the range of $14-14.5$ when covered with mortar mix in saturated with Lithium Hydroxide ( $\mathrm{LiOH})$ and is mostly suitable for the prestressed and post-tensioned concrete works ${ }^{5}$. These anodes works on the principle of sacrificial protection i.e. when two dissimilar metals are placed in an electrolyte (in our case concrete) the most active metal (zinc) will sacrifice itself to protect the more noble (less active) reinforcing steel. The sacrificial anodes can be used in both the cases i.e. during construction and during repair/rehabilitation because of its simplicity to install as shown in Figure 4. V. Rajendran and R. Murugesan ${ }^{5}$ concluded that corrosion resistance of concrete can be improved by using Self Sacrificial Zinc Anodes in RC structures where durability is a prime concern.

\subsection{Potentiodynamic Anodic Polarisation:}

The method of classification of a metal sample by its current-potential connection is Potentio-dynamic Anodic Polarisation. The sample is first scanned in positive going direction to get measurements for detecting the corrosion characteristic of specimen in aqueous environment and then a thorough current-potential plot of sample can be measured in minutes. Using this technique, the effects and passivation tendencies of inhibitors or oxidisers can be investigated easily ${ }^{19}$.
This is an artificial method to corrode the sample which helps in predicting the long term behaviour of materials to a particular environment and also rapidly identifies the desirable environment for material which is helpful to protect the specimen from aggressive attacks from environment. This method is not useful for real time corrosion monitoring and hence not mostly used.

\subsection{Fibre Optics Method}

An elastic component of dielectric material having ability to trap optical energy at one end and guiding it to other end is Fibre Optics. It is an emerging technology having advantages like it is corrosion free, has long duration strength, allows remote checking, free from electromagnetic interference, dodging unwanted noise and many more ${ }^{20-21}$ which makes it overcome the limitations of other kind of sensors. Adaptability of optics fibres and ease in embedding with concrete makes its worth in civil engineering ${ }^{22}$.

Using fibre optics systems embedded in structural elements, Giuseppina Uva et al. ${ }^{21}$ monitored a prestressed $\mathrm{RC}$ viaduct in Bari, Italy with two objectives: controlling structural efficiency during construction phase and periodically checking the structural performance under service loads. The method proved effective for real time structural monitoring for control of strategic buildings and infrastructures.

Recently for RC structures, various fibre optics based crack sensors are developed e.g. to differentiate between the presence and absence of corrosion, sensing based on fibre breakage is done ${ }^{23}$ which fails in providing info on steady structural deprivation. To identify and to monitor the opening of a crack Ansari and Navalukar ${ }^{24}$ developed a "Point" sensor which works only in priori (a small region where cracking occurs). It is proven that this technology can be applied in fields for long term monitoring of $\mathrm{RC}$ structures and play a main character in real time structural health monitoring.

\subsection{High Frequency UV Method}

An Ultrasonic approach is chosen for corrosion monitoring in $\mathrm{RC}$ structures due to its comparative feasibility using an implanted ultrasonic sensor network. The solution comprises of phase velocity, frequency and weakening in $\mathrm{RC}$ structures. Longitudinal, torsional and flexural are the types of propagating waves in cylindrical waveguide ${ }^{25-26}$. Longitudinal waveforms have axial and radial displacements, torsional waveforms have angular displacements and flexural waveforms have all three types of displacements. The notation used to represent these waveforms are $\mathrm{L}(\mathrm{m}, \mathrm{n}), \mathrm{T}(\mathrm{m}, \mathrm{n})$ and $\mathrm{F}(\mathrm{m}, \mathrm{n})$ resp. where character " $\mathrm{m}$ " signify circumferential displacement (function of $\cos (m \theta)$ ) besides " $n$ " the consecutive order of the mode. The guided wave propagation in rebar is affected by corrosion process by two ways: (i) alteration in bond which affects the quantity of waveform energy leaked to adjacent and (ii) discontinuities producing scattering, reflections and mode conversions of waveform. 


\section{CONCLUSION}

From the above discussion, it can be concluded that OCP, Sp, LPR, Potentio-dynamic Anodic Polarisation techniques are useful in finding anodic and cathodic sites but they fail in providing information on real time corrosion monitoring. Newly developed methods like AE, Galvanic Monitoring Probe, FO, High Frequency UV methods overcome the limitation of real time monitoring. FO method is already studied on a viaduct. AE can be improved by embedding advanced sensors in RC structures. High frequency UV method require more study for implementing in real time corrosion monitoring.

\section{NOTATION}

\begin{tabular}{|c|c|}
\hline A & Surface Area of Steel $\left(\right.$ in $\left.\mathrm{cm}^{2}\right)$ \\
\hline $\mathrm{AbE}$ & Absolute Energy \\
\hline $\mathrm{AE}$ & Acoustic Emission \\
\hline ASL & Average Signal Level \\
\hline ASTM & American Standard of Testing Material \\
\hline B & Stern-Geary constant \\
\hline $\mathrm{CO}_{2}$ & Carbon Dioxide \\
\hline $\mathrm{d}$ & Density (in $\mathrm{g} / \mathrm{cm} 2$ ) \\
\hline E.W. & Equivalent Weight (in g/eq.) \\
\hline $\mathrm{Fe}_{2} \mathrm{O}_{3}$ & Ferric Oxide \\
\hline $\mathrm{HCP}$ & Half-Cell Potential \\
\hline $\mathrm{HDD}$ & Hit Driven Data \\
\hline$i_{\text {corr }}$ & Corrosion Current Density \\
\hline LPR & Linear Polarisation Resistivity \\
\hline NDT & Non-Destructive Technique \\
\hline $\mathrm{O}_{2}$ & Oxygen \\
\hline OCP & Open Circuit Potential \\
\hline $\mathrm{pH}$ & Potential of Hydrogen \\
\hline $\mathrm{RC}$ & Reinforced Concrete \\
\hline $\mathrm{RCC}$ & Reinforced Cement Concrete \\
\hline Rp & Polarisation Resistance \\
\hline S M ASCE & Student Member of American Society of Civil Engineers \\
\hline SP & Surface Potential \\
\hline TDD & Time Driven Data \\
\hline
\end{tabular}

\section{REFERENCES}

[1] Montemor M.F., Simoes A.M.P. and Ferreira M.G.S., "Chloride-Induced Corrosion On Reinforcing Steel: From The Fundamentals To The Monitoring Techniques", Cement \& Concrete Composites Journal, V. 25, 2003, pp. 491-502

[2] Song Ha-Won and Saraswathy Velu, "Corrosion Monitoring of Reinforced Concrete Structures - A Review", International Journal on Electrochemical Science, V. 2, 2007, pp. 1- 28

[3] Liu T. and Weyers R.W., "A modelling the Dynamic Corrosion Process in Chloride Contaminated Concrete Structures", Cement and Concrete Research Journal, V. 28, No. 3, 1998, pp. 365-379

[4] Carino N. J, "Non-Destructive Techniques to Investigate Corrosion Status in Concrete Structures", Journal of Performance of Constructed Facilities, V. 13, August 1999, pp. 96-106

[5] Matthew, D., Pritzl E. I. T., "Deterioration of Reinforced Concrete Element", Interface Journal, March 2008, pp. 23-30

[6] Rajendran V. and Murugesan R., "Study on Performance of Self Regulating Sacrificial Galvanic Anodes with and without Preconditioning against Control Specimen and using Accelerated Corrosion", Asian Journal Of Civil Engineering (Bhrc), Vol. 14, No. 2 , 2013, pp. 181-199

[7] Soleymani H. R., Ismail M. E., "Comparing Corrosion measurement methods to assess the corrosion activity of laboratory OPC and HPC concrete specimens", Cement and Concrete Research Journal, V. 34, No. 11, Nov. 2004, pp 2037-2044

[8] ASTM C876-91, "Standard Test Method for HalfCell Potentials of Uncoated Reinforcing Steel in Concrete", 1999.

[9] Sagües A., "Corrosion measurement techniques for steel in concrete”, Corrosion Journal, 1993, pp 353.

[10] Videm K., "Corrosion of reinforcement in concrete. Monitoring, prevention and rehabilitation”, EFC no. 25. London, 1998, pp. 104-121

[11] Yeih W. and Huang R., "Detection of the Corrosion Damage In Reinforced Concrete Members By Ultrasonic Testing", Cement and Concrete Research Journal, V. 28, No. 7, 1998, pp. 1071-1083

[12] Stern M. and Geary A. L., "Electrochemical Polarization I. A Theoretical Analysis of the Shape of Polarization Curves", Electrochemical Society Journal, V. 104, No. 1, 1957, 56-63

[13] Gowers K. R., Millard S. G., Gill J. S. and Gill R. P., "Programmable Linear Polarisation Meter for Determination of Corrosion Rate of Reinforcement in Concrete Structures", V. 29, No. 1, Jan 1994, pp. 2532

[14] Kaewkongk T., Lim J., Kanjanaprayut N. and Daopiset S., "Corrosion Monitoring using Acoustic Emission and Potentiodynamic method", IEEE International Instrumentation and Measurement Technology Conference 
[15] Mangual J., ElBatanouny M., Ziehl P. and Fabio Matta, "Corrosion Damage Quantification of Prestressing Strands Using Acoustic Emission", Materials In Civil Engineering Journal (C) ASCE, Sept 2013, pp. 1326-1334

[16] Benedetti M. D., Loreto G., Matta F. and Nanni A., "Acoustic Emission Monitoring of Reinforced Concrete under Accelerated Corrosion", Materials In Civil Engineering Journal (C) ASCE, Aug. 2013, pp. 1022-1029

[17] Brooman E. W., "Corrosion Performance of Environmentally Acceptable Alternatives to Cadmium and Chromium Coatings: Chromium-Part II", Metal Finishing Journal, V. 98, No. 8, Aug. 2000, pp. 39-45

[18] Ohtsu M. and Tomoda Y., "Phenomenological Model of Corrosion Process $n$ Reinforced Concrete Identified By Acoustic Emission." ACI Materials Journal, 105(2), 2008, pp. 194-199

[19] Gulikers J., "Development of a Galvanic Monitoring Probe to Improve Service Life Prediction of Reinforced Concrete Structures with Respect to Reinforcement Corrosion", Construction and Building Materials Journal, V. 11, No. 3, 1997, pp. 143-148

[20] Aradilla D., Estrany F. and Alemán C., "Different Properties for Poly (3,4ethylenedioxythiophene) Films Derived from Single or Multiple
Polymerization Steps", Applied Polymer Science Journal, V. 121, No. 4, Aug. 2011, pp. 1982-1991

[21] Casas J. R. and Cruz P. J. S., "Fiber Optic Sensors For Bridge Monitoring", Bridge Engineering Journal (C) ASCE, Dec.2003, pp. 362-373.

[22] Uvaa G., Porcoa F., Fiorea A. and Porcob G., "Structural Monitoring Using Fibre Optic Sensors of Apre-Stressed Concrete Viaduct During Construction Phases", Case Studies in Non-Destructive Testing and Evaluation2, 2014, pp. 27-37

[23] Ansari F., "Theory and Applications of Integrated Fibre Optic Sensors in Structures.' Intelligent civil engineering materials and structures Journal (C) ASCE, 1997, pp. 2-28.

[24] Rossi P. and LaMaou F., "New Method for Detecting Cracks in Concrete Using Fibre-Optics", Materials and structures Journal, V. 22, No. 132, 1989, pp. 437-442

[25] Ansari F. and Navalurkar R. K., "Kinematics of Crack Formation in Cementitious Composites by Fiber Optics"', Eng. Mech. Journal, V. 119, No. 5, 1993, pp. 1048- 1061.

[26] Ervin B. L., Kuchma D. A., Bernhard J. T. and Reis H., "Monitoring Corrosion of Rebar Embedded in Mortar Using High-Frequency Guided Ultrasonic Waves", Engineering Mechanics Journal (C) ASCE, Jan. 2009, pp. 9-19

\section{FIGURES}

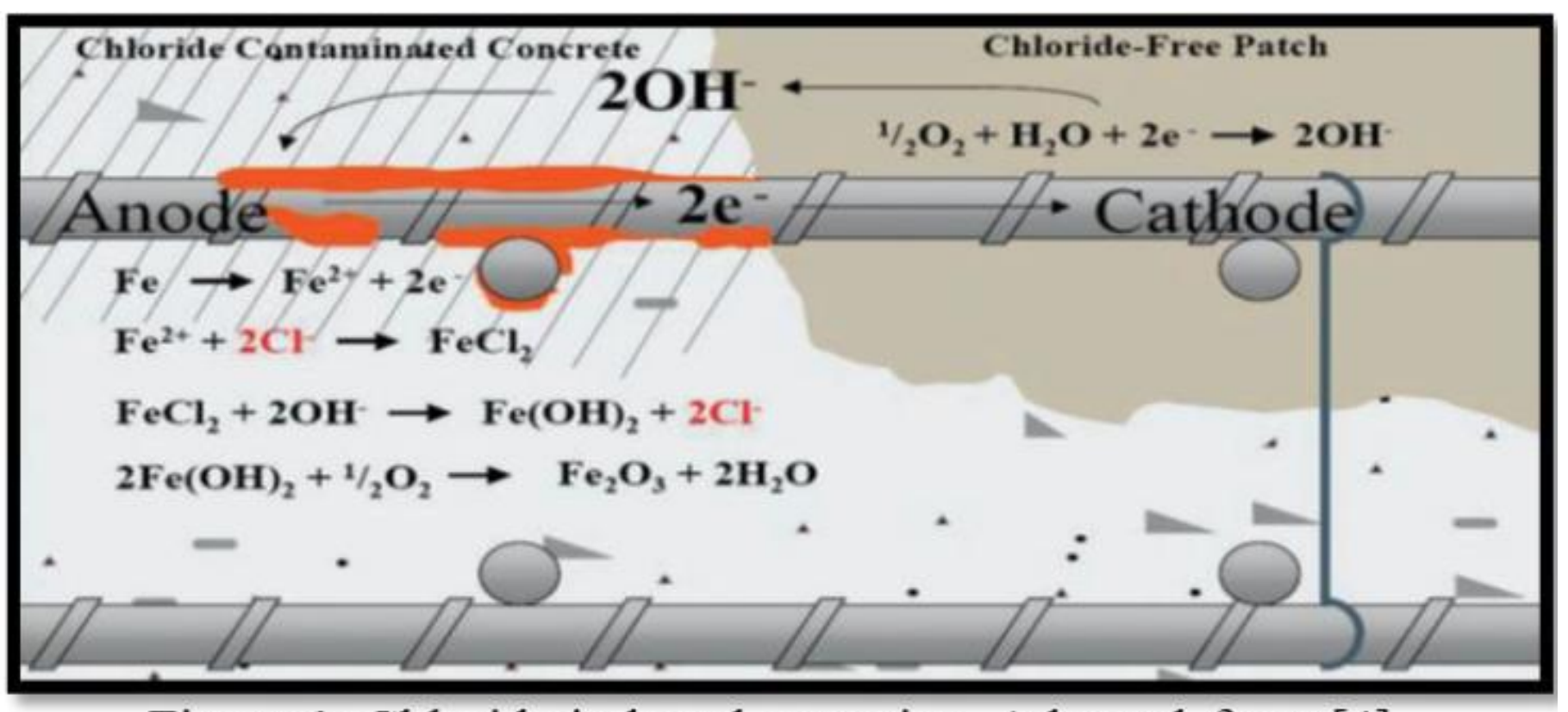

Figure 1: Chloride induced corrosion. Adopted from [4] 


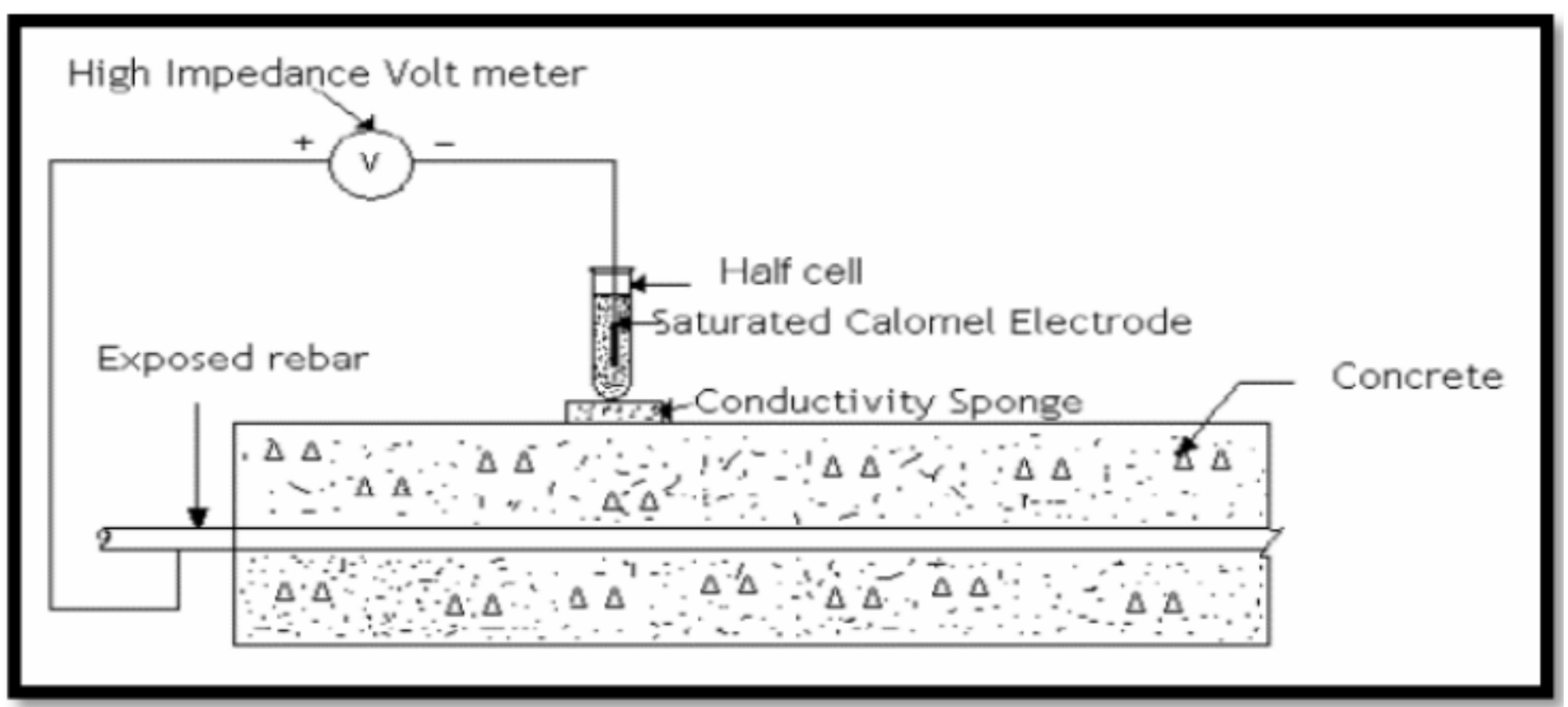

Figure 2: Schematic representation of Open circuit potential (OCP) measurement. Adopted from [2]

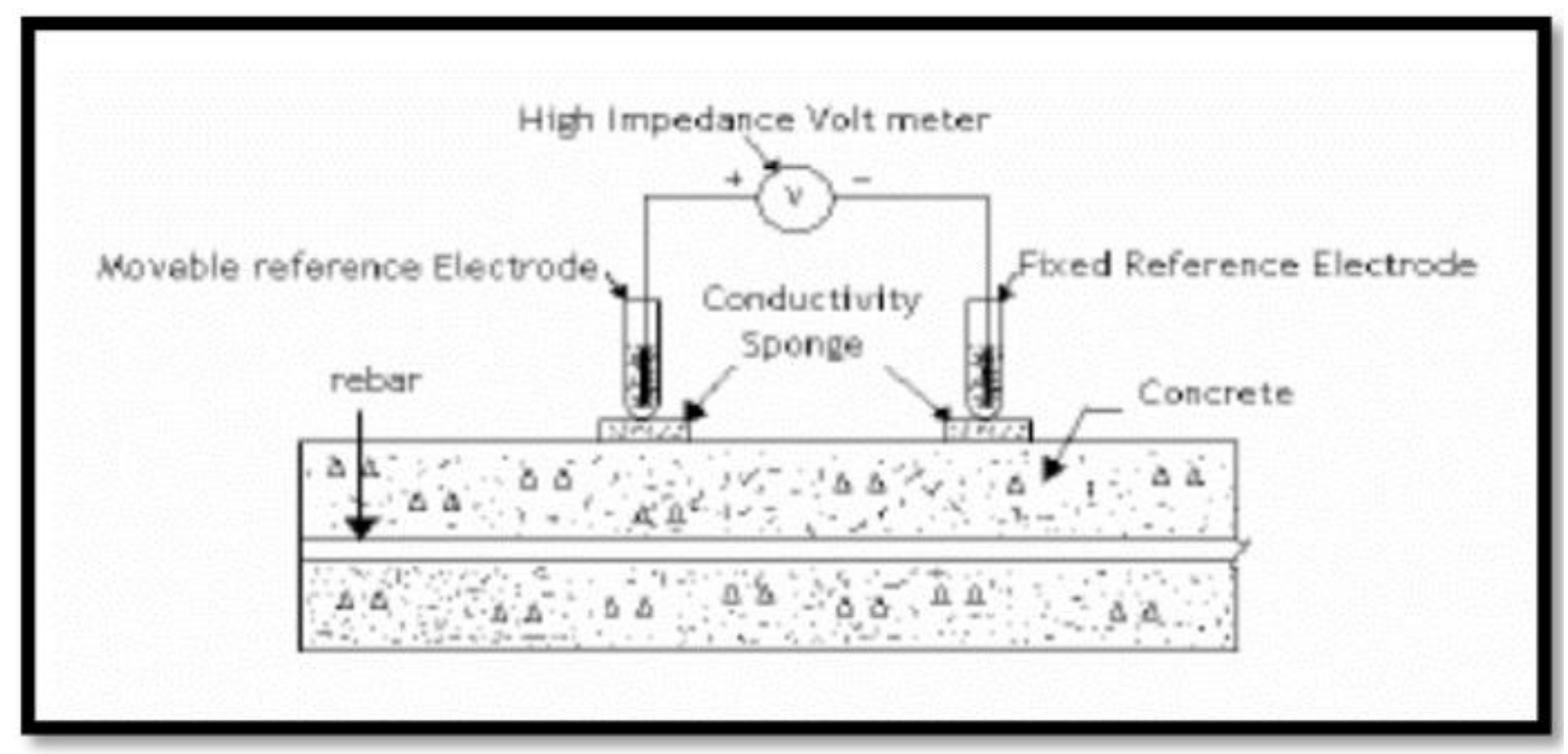

Figure 3: Schematic representation of surface potential (SP) measurements. Adopted from [2] 


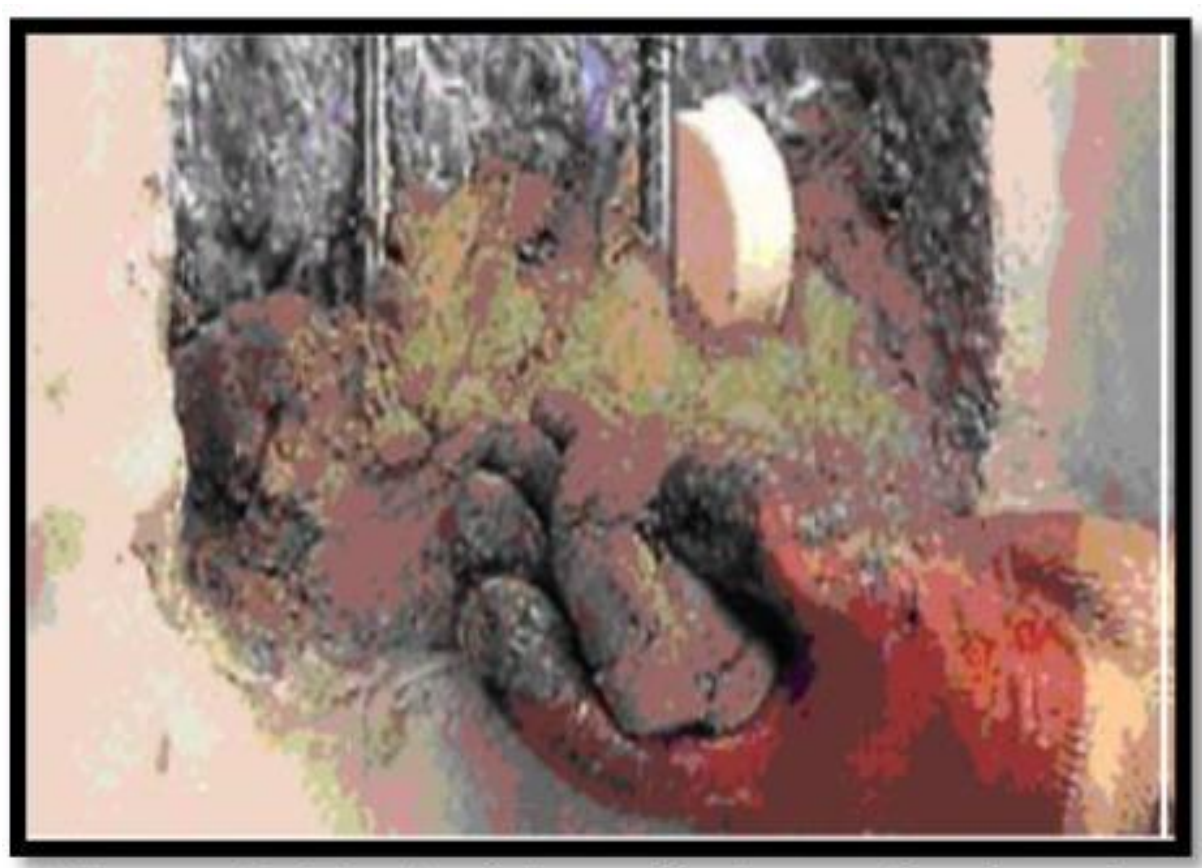

Figure 5: Typical installation of galvanic
anode at site. Adopted from [6] 